\title{
Empirical testing of Balassa-Samuelson hypothesis with German and UK data
}

Josheski, Dushko; Koteski, Cane and Lazarov, Darko University Goce Delcev Stip, University Goce Delcev Stip, University Goce Delcev Stip

29. September 2011

Online at http://mpra.ub.uni-muenchen.de/33803/

MPRA Paper No. 33803, posted 30. September 2011 / 00:02 


\title{
Empirical testing of Balassa-Samuelson hypothesis with German and UK data
}

\author{
Dushko Josheski ( dushkojosheski@gmail.com ) \\ Cane Koteski (cane.koteski@ugd.edu.mk) \\ Darko Lazarov (darko.lazarov@ugd.edu.mk)
}

\begin{abstract}
There are a lot of studies that test Ballasa-Samuelson hypothesis also known as Harrod-BalassaSamuelson effect directly via the effect of productivity, one possible explanation is that PER Capita GDP is not good explanation for productivity (.i.e. Labor productivity) differences; an increase (decrease) in relative efficiency of the distribution sector with respect to foreign countries induces depreciation (appreciation) of the exchange rate. After we obtained the number of co-integrated vectors we continue further to see whether the CV tells us something about the long run relationship into the model, likelihood ratio test of exactly identified restrictions test confirms that constant is insignificant variable therefore we can confirm that there is long-run relationship in which the changes in Exchange rate are positively correlated with the changes of ratio of German Consumer Price Index (CPI) to the UK Retail Price Index (RPI). In order to test for relative PPP to support the theoretical relationship between the variables, restrictions are put on the PPP knowing that PPP and that downward movement in the series indicates increase of UK price level relative to German price level. In each EC model there is an EC mechanism and coefficient on the co integrating vector measures the rate per period at which one of the endogenous variables adjusts. In the first equation the error correction mechanism is highly significant and negative. If the system is out of equilibrium, alteration in the change of the exchange rates will be downward (everything else ceteris paribus) compensating around $68 \%$ of the disequilibrium per year. In the second equation error correction mechanism is also highly significant but positive meaning that if the system is in disequilibrium changes of change in the ratio of German CPI relative to UK Retail Price index will rise offsetting 15\% of the disequilibrium per year until the equilibrium rate of exchange rate will be achieved. Model implies German Labor productivity to UK Labor productivity ratio doesn't have significant influence on explaining on relative change on prices not even on theexchange rate contrary to Pugh, Beachil study
\end{abstract}

Key words: Purchasing power parity, Exchange rate, co integration, error correction model, productivity, Consumer Price Index, Retail Price Index, 
1. Unit Root test ADF-Percon procedure conducted on STDMER70, PPP70, PRDRATIO

There are a lot of studies that test Ballasa -Samuelson ${ }^{[2}$ hypothesis directly via the effect of productivity ${ }^{(7)}$ ie. Labour productivity ${ }^{(4)}$. Since in the paper it is not tested for unit root conditional upon structural breaks here is applied modified ADF/Pecron test ${ }^{\text {(3) }}$

The $\mathrm{H}_{0}$ : time series has a unit root with possibly non-zero drift aga inst the alternative that the process is trend stationary

$$
\begin{gathered}
y_{t}=\mu_{1}+y_{t-1}+d D(T B)+\left(\mu_{2}-\mu_{1}\right) D U_{T}+\varepsilon_{t} \\
D(T B)_{t}=1 \text { if } t=T_{B}+1,0 \text { otherwise } \\
D U_{t}=1 \quad \text { if } t>T_{B} \quad \text { ootherwise } \\
\text { And } A(L) e_{T}=B(L) v_{t} v_{t} \sim\left(0, \sigma^{2}\right)
\end{gathered}
$$

\section{Plot of data}

Plot of $\frac{U K}{\text { German }}$ productivity ratio supports the idea of structural break in 1980 with movement

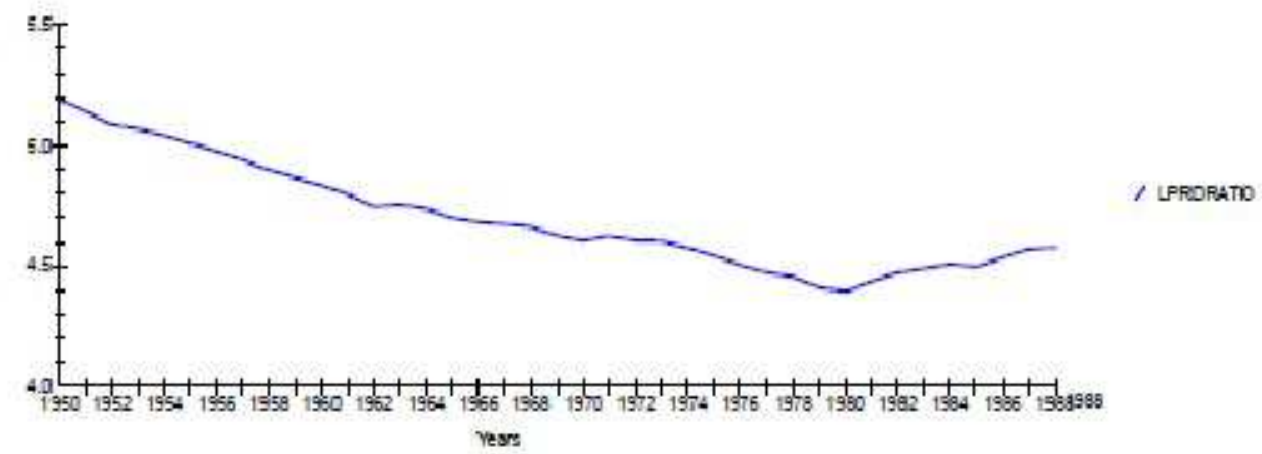

1 See Appendix 1 Variable definition

${ }^{2}$ Also known as Harrod-Balassa-Samuelson effect (Knavis and Lipsey 1983)

3 One possible explanation is that PER Capita GDP is not good explanation for productivity differences; an increase (decrease) in relative efficiency of the distribution sector with respect to foreign countries induces depreciation (appreciation) of the Exchange Rate.

4 Beachill Bob; Pugh Geoffrey (1998) Monetary cooperation in Europe and the problem of differential productivity growth. International Retiew of Applied Economics, Vol.12, No 3 (Sept.1998) pp.455-57

${ }^{5}$ Pierre Perron(1989) The Great crash, the oil stock and the writ root hypothesis 
from downwards to upwards in $1980^{\circ}$. Plot of the first difference of the $\log$ form ${ }^{\circ}$.did not revel conclusion about the serial movement.

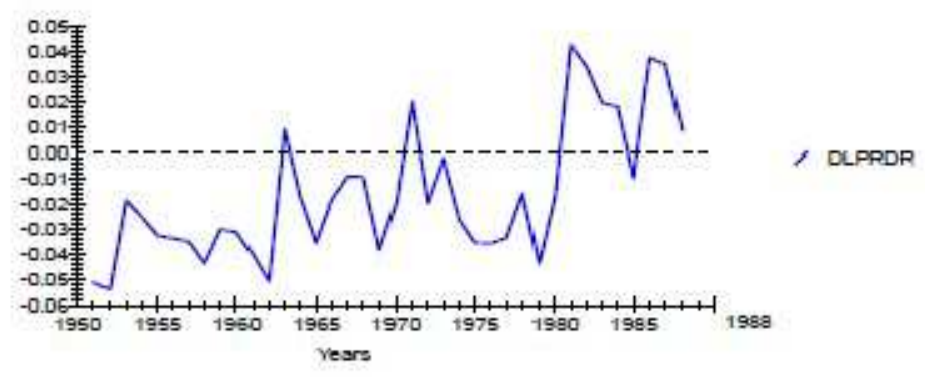

Table 1 List of the data

\begin{tabular}{|r|r|r|}
\hline & LPRDR & DLPRDR \\
\hline 1978 & 4.4555 & -0.01613 \\
\hline 1979 & 4.4116 & -0.04392 \\
\hline 1980 & 4.3944 & -0.01714 \\
\hline 1981 & 4.4368 & 0.042302 \\
\hline 1982 & 4.4705 & 0.033744 \\
\hline 1983 & 4.4898 & 0.019264 \\
\hline
\end{tabular}

List of the data shows switch of the data from deceasing to increasing trend and for DLPRDR switch from negative to positive values. Graphically it can be shown that PRDRATIO is I(2) variable. But the previous plot shows that PPP70 van be $\mathrm{I}(2)$ variable also.

\footnotetext{
6 $1979-1980$ marked a change in UK supply side policy accondingly it is taken 1981 as the year after the structural break which is confirmed by the data plot

${ }^{7}$ Log form it is taken as more appropriate even though all data are plotted see appendix 1
} 


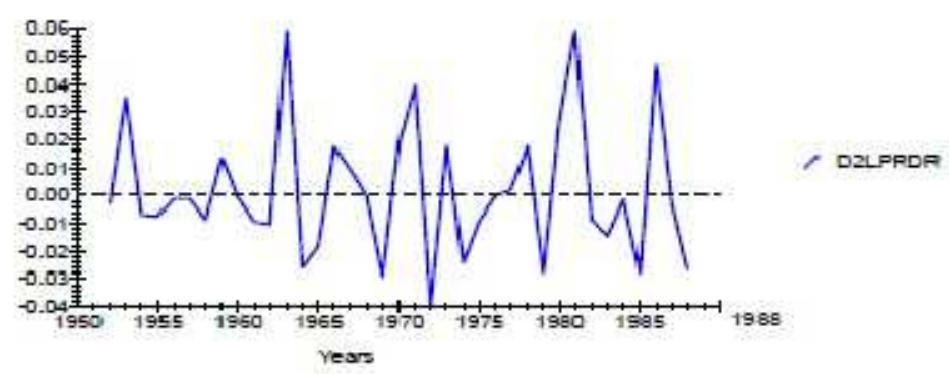

Plotting the data for PPP70 purchasing power parity variable $2^{N D}$ difference of the log of PPP70 is $I(0)$

18

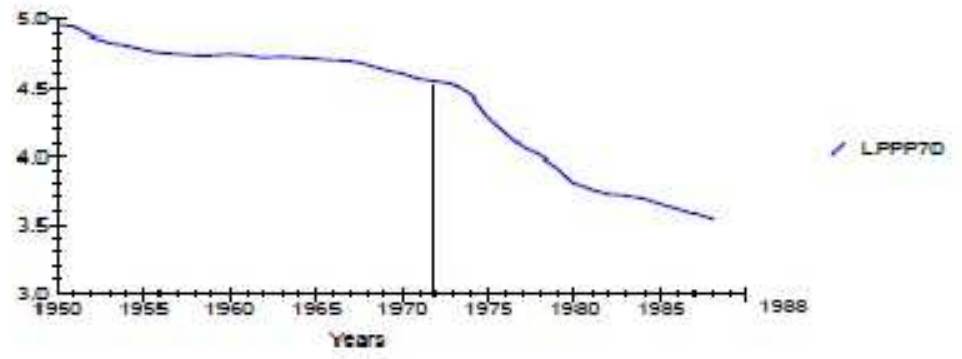

Plot of the PPP70 variable shows existence of the structural break in 1974

${ }^{8}$ Which theoretically as it is known marks the breakdown of Bretton woods system of fixed Exchange Rates 


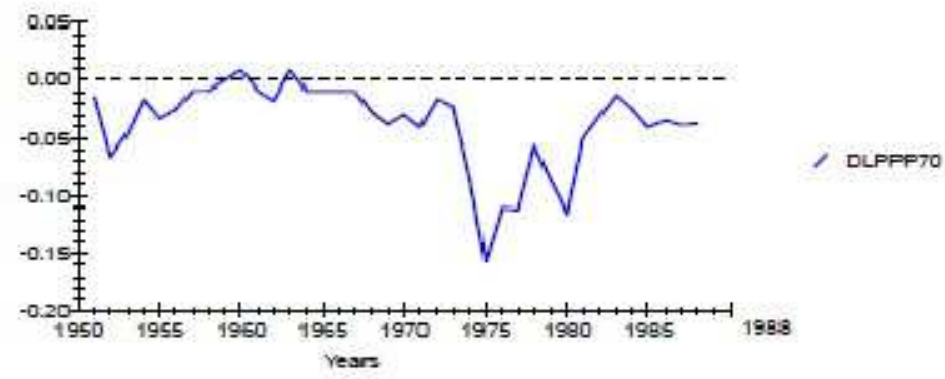

Plot of the first difference of the log level of PPP70 does not reveal conclusion about the serial movement $\mathrm{I}(1)$

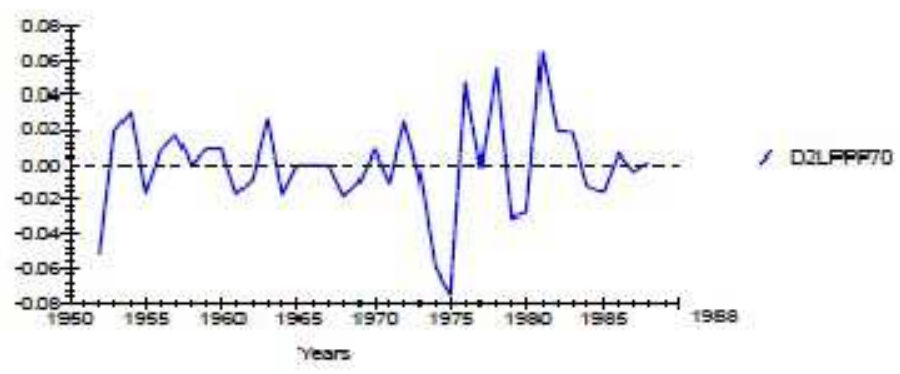

Plot shows that D2IPPP70 is stationary I $(0)$

Table 2 List of the data

\begin{tabular}{|r|r|r|}
\hline & LPPP70 & DLPPP70 \\
\hline 1971 & 4.5643 & -0.04082 \\
\hline 1972 & 4.5486 & -0.01575 \\
\hline 1973 & 4.5261 & -0.02247 \\
\hline & & \\
1974 & 4.4438 & 0.082300 \\
\hline 1975 & 4.2863 & -0.15749 \\
\hline 1976 & 4.1759 & -0.11042 \\
\hline
\end{tabular}

After the break down of Bretton Woods there is continuation in decreasing trend of the variable and there is a shift in the first difference form negative to positive 
a. ADF / Perron test unit root test for the STDMER70 variable

\begin{tabular}{|c|}
\hline$D E R 70=I n t+\theta D_{u t}+\beta T i m+\gamma D T_{t}+\delta D T B_{t}+\widehat{\beta}_{1} y_{t-1}+\sum_{i=k}^{k} \hat{c} \Delta y_{t-1}+\hat{e}_{t}{ }^{10}$ \\
\hline$D L E R 70=I n t+\theta D_{u t}+\beta T I M+\gamma D T_{T}+\delta D T B_{t}+\widehat{\beta}_{1} L y_{t-1}+\sum_{i=k}^{k} \hat{c} \Delta y_{t-1}+\hat{e}_{t}{ }^{11}$ \\
\hline$D 2 L E R 70=I n t+\theta D_{u t}+\beta T I M+\gamma D T_{t}+\delta D T B_{T}+\widehat{\beta}_{1} L y_{t-1}+\sum_{i=k}^{k} \hat{c} \Delta y_{t-1}+\hat{e}_{t}{ }^{12}$ \\
\hline$D 2 E R 70=I n t+\theta D_{u t}+\beta T I M+\gamma D T_{t}+\delta D T B_{t}+\widehat{\beta}_{1 y t-1}+\sum_{i=k}^{k} \hat{c} \Delta y_{t-1}+\hat{e}_{t}{ }^{13}$ \\
\hline
\end{tabular}

Model C defined by Perron(19899) ${ }^{(14)}$ is fully specified and it takes all the various changes in time series into account. All three variables are being tested

DTBER70 dummy variable for the immediate change after the break in it models a onetime change in the intercept and is $=1 ; \mathrm{DV}=1$ if $t=t_{b}+1$; otherwise 0 ;

DUER70 dummy variable DUER $70=1$; if $t>T B$; otherwise 0 ; changes in the drift parameter in every period after the break;

DTER70-dummy variable if $t>T B$; otherwise 0 allows for a changes in the slope of the trend function

TIM- deterministic time trend

TB - time break from theoretical knowledge and by plotting the data we suspect that it is 1967 sterling stabstantial devaluation (see plot of the log level of the STDMER 70 ) variable 1968 is equal to $\mathrm{TB}+1$

\footnotetext{
${ }^{9}$ Variables definitions see Appendix 1 Section A

${ }^{10}$ This model is tested in log terms as it is in levels see Appendix 2 Section B

${ }^{11}$ This is a log form of the model first difference in a logs DLER70 and log of the dependent varia ble level form. See Appendix 2 part 22 a

12 See Appendix $3 a$ ADF/Perron test fo the log levels of the variables of interest

${ }^{13}$ See Appendix 2 section 2 part 1 a variables ADF Perren test for $1^{\text {st }}$ differences of the variables of interest this all 4 equations in the remaining text will be reffered as equation $1,2,3,4$.

${ }^{14}$ HO:UNIT ROOT conditional on drift deterministic trend and 3 types of structural break
} 


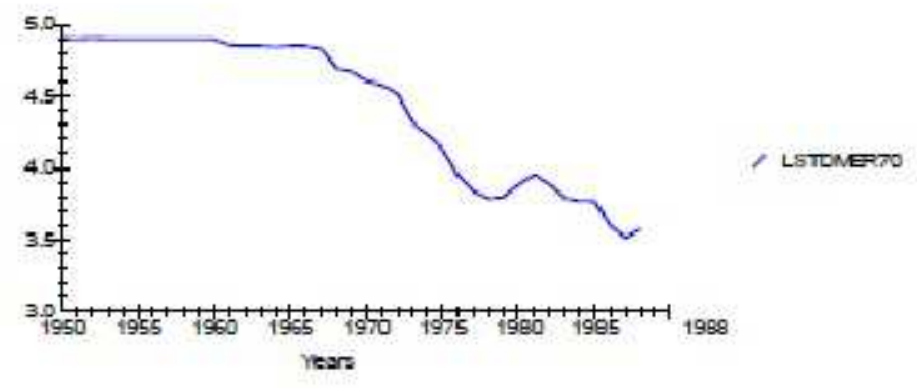

Plot of the data of the log level of STDMER70 variable confirms existence of structural break in 1967

\section{Equation 1}

1. For the equation $1 \mathrm{t}$-statistics on the lagged value of the series is -1.65 time of the break relative to total sample size $\lambda=\frac{19}{39}=0,48 \sim 48 \%$

Sample size $=39$ observations . $5 \%$ critical value between $-4.22(\lambda=40 \%)$ and $-4.24(\lambda=50 \%)$

$$
\mathrm{H}_{0} \text { : unit root cannot be rejected }
$$

We cannot reject the null hypothesis

No serial correlation $p$-value $=(.113)$ AT 7 LAGS functional form is well specified

\section{Equation $2^{(15)}$}

2. For the equation $2 \mathrm{t}$-statistics on the lagged value of the secies is -2.46 time of the break relative to the sample size is $\lambda=48 \%$

Sample size $=39$ observations $5 \%$ critical value between $|4.22|$ and $|4.24|$ and null hypothesis of unit root existence cannot be rejected and hypothesis of no secial correlation p-value (0.634) Fpvalue (0.696) AT 3 LAGS functional form well specified

\footnotetext{
${ }^{15}$ See Appendix 2 section 2 a critical values for $\lambda$ can be found in Perron( 198:9)
} 


\section{Equation 3}

3. For the equation $3 \mathrm{t}$-stat on the lagged value of time series is -2.72 time of the break relative to the sample size $\lambda=48 \%$ Sample size is 39 observations we accept the form with no lags and DW statistics which is valid if on the right hand side of the equation there are no lags shows no serial correlation (2.0796) and type 1 error of making mistake if we reject the null of no secial correlations is $48 \%$ o lags of the dependent variable

\section{Equation $4^{(17)}$}

4. For the equation $4 \mathrm{t}$ stat on the lagged value of the time series -1.73 . Probability of type 1 error of making mistake if we reject the mull of no serial correlation $95 \%$ the mull hypothesis of no unit root cannot be rejected WITH 1 LAG of the dependent variable

Having in mind possible multicollinearity we accept equation with no lags of the dependent variable on RHS (Equation 3) for further analysis

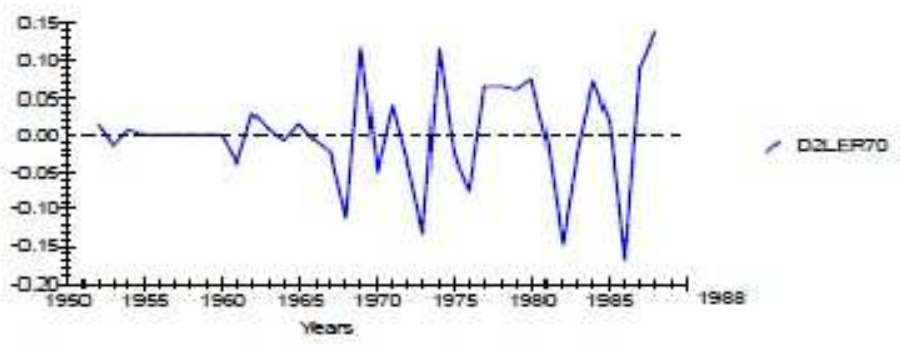

$1^{\text {t* }}$ difference of the log level of UK sterling exchange rate/DM is I(O)

\footnotetext{
${ }^{16}$ See Appendix 3 Section 3

${ }^{17}$ See Appendix 2 section 1a
} 
b. DF/ADF / Perron test unit root test for the PPP70 variable

For this regression were created the following terms

DTBPPP 70 time of the breal dunumy cariable $=1$ if $t=T_{b}+1$ immediately after the breat:

1974 (see plot of the data above)

DUPPP70 DV $=1$ for all periods immediately after the break ( 1974 1988)

$D T P P P 70=T T M E$ TREND if $\mathrm{D}>\mathrm{TB}$; otherwise 0 ;

Equation1
DPP $70=\operatorname{lnt}+\theta D P P P 70_{\text {ut }}+\beta T i m+\gamma D T P P P 70_{t}+\delta D T B P P P 70_{t}+\hat{\beta}_{1} y_{t-1}+\sum_{t=k}^{k} \hat{\varepsilon} \Delta y_{t-1}+\hat{e}_{t}$

1 LAG of the dependent variable $\lambda=\frac{26}{39}=0,66 \sim 66 \%$ for $5 \%$ level of significance critical value is $-4.24(60 \%)$ and $-4.18(70 \%) \mathrm{t}$-stat on the lagged time series is -4.19 it is between the interval and the mill hypothesis that the unit root cannot be rejected is accepted ie. insufficient evidence to reject at conventional levels of significance

Equation 2 (19)

$D L P P P 70=I n t+\theta D P P P 70_{u t}+\beta T I M+\gamma D T P P P 70_{T}+\delta D T B P P P 70_{t}+\hat{\beta}_{1} L y_{t-1}+\sum_{t=k}^{k} \hat{c} \Delta y_{t-1}+\hat{e}_{t}$

1 lag of the dependent variable t-stat on the lagged time series is -3.78 the null hypothesis of unit root cannot be rejected and the null hypothesis of no serial correlation cannot be rejected at conventional levels of significance i.e. probability of committing type 1 error is $72 \%$.

Equation $3^{(20}$

$D 2 L P P P 70=I n t+\theta D P P P 70_{u t}+\beta T I M+\gamma D T P P P 70_{t}+\delta D T B P P P 70_{T}+\hat{\beta}_{1} l y_{t-1}+\sum_{l=k}^{k} \hat{c} \Delta y_{t-1}+\hat{\epsilon}_{t}$

$O$ lags of the dependent variable the $t$-stats of the lagged time series in the equation is -2.93 and the null hypothesis at $5 \%$ for values of $\lambda=-4.24(60 \%)$ and $-4.18(70 \%)$ cannot be rejected and mull hypothesis of no secial correlation cannot be rejected at $5 \%$ conventional level of significance by large sample test Langrange which follows $\chi^{2}$ distribution and $1 \%, 5 \%, 10 \%$, level of significance by small sample technique $\mathrm{F}$ test $\mathrm{p}$-value $10,6 \%$

Equation $4^{(21)}$

$D 2 P P P 70=I n t+\theta D P P P 70_{u t}+\beta T I M+\gamma D T P P P 70_{t}+\delta D T B P P P 70_{t}+\widehat{\beta}_{1 y t-1}+\sum_{i=k}^{k} \hat{e} \Delta y_{t-1}+\hat{e}_{t}$

1 lag of the dependent variable the t-stats of the lagged time series in the equation is -6.24 and there is sufficient evidence to reject null of unit root DW is a general diagnostic test ${ }^{123}$ and its value 1.9 shows no serial correlation and functional form is well specified.

\footnotetext{
${ }^{18}$ See Appendix 2 Section 1 b

${ }^{19}$ See Apendix 2 Section 2 part $2 b$

${ }^{20}$ See Appendix 2 Section 3 part 3b

${ }^{21}$ See Appendix 2 Section 2 PART $1 \mathrm{~b}$

${ }^{22} \mathrm{DW}=2(1-\hat{\rho})$
} 
c. ADF / Perron test unit root test for the PRDRATIO variable

For these 4 models we created following Perron's terms

DTBPRDR $=1 ;$ IF T $=$ TB +1 otherwise 0 ; from the other plot above is 1980 and year after the break is 1981;

DUPRDR $=1$ IF $\mathrm{t}>\mathrm{TB}$; otherwise 0 ;

$D T P R D R=T$ if $\mathrm{t}>\mathrm{TB}$; otherwise 0 ; which allows for a sudden change in the slope of the trend

Equation 1

$D P R D R=I n t+\theta D P R D R_{u t}+\beta T i m+\gamma D P R D R_{t}+\delta D T B P R D R_{t}+\hat{\beta}_{1} y_{t-1}+\sum_{t=k}^{k} \hat{d} \Delta y_{t-1}+\hat{e}_{t}$

O lags of the dependent variable $\lambda=\frac{32}{39}=8: 2 \%$ t-stat on the lagged time series is -2.41 while values for $\lambda$ from the tables are $-4.04(80 \%)$ and $-4.10(90 \%)$ and the null of existence of unit root cannot be rejected

Equation 2 (24)

$$
D L P R D R=I n t+\theta D P R D R_{u t}+\beta T I M+\gamma D T P P R D R_{T}+S D T B P R D R_{t}+\hat{\beta}_{1} L y_{t-1}+\sum_{t-k}^{k} \hat{e} \Delta y_{t-1}+\hat{e}_{t}
$$

0 lags of the dependent variable $t$-stat of the lagged value of time series -2.44 and the null hypothesis of unit root cannot be rejected probability of type 1 error when rejecting the null of no secial correlation is $72 \%$

Equation $3^{[25]}$

$$
D 2 L P R D R=I n t+\theta D P R D R_{\mathrm{UI}}+\beta T I M+\gamma D T P R D R_{t}+\delta D T B P R D R_{T}+\hat{\beta}_{1} L y_{t-1}+\sum_{t-k}^{k} \hat{e} \Delta y_{t-1}+\hat{e}_{t}
$$

3 lags of the dependent variable t-stat of the lagged value of time series is -3.01 and the null hypothesis of not rejecting the unit root there is sufficient evidence to accept at te conventional levels of significance and no serial correlation cannot be rejected ${ }^{(3)}$

Equation 4 (स)

$$
D 2 P R D R=I n t+\theta D P R D R_{\text {ut }}+\beta T I M+\gamma D T P R D R_{t}+\delta D T B P R D R_{t}+\widehat{\beta}_{1 y t-1}+\sum_{i-k}^{k} \hat{c} \Delta y_{t-1}+\hat{e}_{t}
$$

1 LAG of the dependent variable $t-s$ tat of the lagged value of time secies is -2.41 and the null hypothesis of no unit root cannot be rejected probability of type 1 error when rejecting the null of no serial correlation $12.3 \%$

\footnotetext{
${ }^{23}$ See Append ix 2 Section 1 b

${ }^{24}$ See Appendix 2 section $2 c$

${ }^{25}$ See Append ix 2 section 3 part $3 c$

${ }^{26}$ Probability of type 1 error is 14.796

${ }^{27}$ See Append ix 2 Section 3 part 3
} 
For the purpose of the cointegration analysis 3 equations are chosen according to the diagnostics and number of lags we choose the following equations

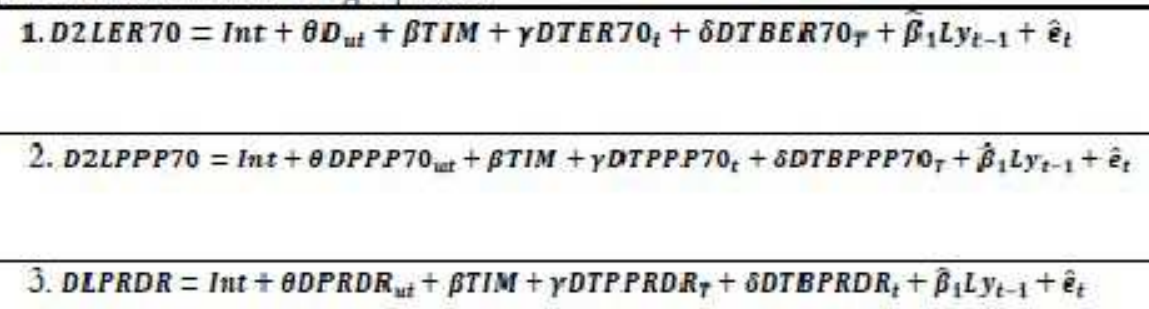

None of the models suffers from the serial correlation and all contain zero lags of the dependent variable. Variable deletion test showed that in each of the equations (DU, DT,DTB) are jointly significant at $1 \%, 5 \%, 10 \%$ levels of significance (see Appendix 3 Section a). For the vaciables to be cointegrated linear combination should be $\mathrm{I}(0)$.

\footnotetext{
${ }^{28}$ Holden Ken Thompson John (1992) Co-integration an-Introductary survey , Brotish reiew of Economic Issues
} 